\title{
A mineração aurífera na ocupação do planalto curitibano e litoral paranaense (séculos XVI-XVIII)
}

\author{
Jefferson Picanço* \\ Maria José Mesquita**
}

\section{Resumo}

O território que hoje chamamos Planalto Curitibano e Litoral Paranaense foi um território incorporado à esfera da colonização portuguesa em meados do século XVII, como conseqüência da expansão da economia paulista para o sul. No início do século XVII, ambas as áreas eram zonas de escravização indígena pelos paulistas. Posteriormente, passam a ser zonas de lavra de aluviões auríferos. As vilas de Paranaguá e Curitiba foram fundadas no período de mais intensa exploração do metal. Com a descoberta do ouro em Minas Gerais a mineração na região entrou em declínio. No século XVIII, com o estabelecimento da "estrada do sertão", ligando os campos sulinos às novas regiões mineradoras, desenvolveu-se uma segunda fase de fundação de novas vilas, relacionadas com a atividade campeira. A decadência da mineração

Geologist (1989), MsC (1994) and PhD (2000) at the University of São Paulo. Since 2010, professor at the Geoscience Education and History program (undergraduate and graduate courses) at the University of Campinas, UNICAMP (Brazil). His studies aim the Brazilian colonial mining and cartography, with emphasis in Sao Vicente and Goiás areas (XVII and XVIII centuries respectively)

** Geologist (1985), MsC (1991) and PhD (1996) at the Federal University of Rio Grande do Sul. Former professor at Federal University of Paraná. Since 2011, professor at the Geoscience Education and History program (undergraduate and graduate courses) at the University of Campinas, UNICAMP (Brazil). His studies aim in Geosciences Education and Economic Geology

Geosul, Florianópolis, v. 27, n. 54, p 117-137, jul./dez. 2012 


\begin{abstract}
AQUI
e a instalação de outras atividades econômicas foram responsáveis pelo reordenamento de ambas as regiões, num processo que leva todo o século XVIII. A formação das vilas de São José dos Pinhais, próximo das lavras do Arraial, e de Morretes, nas lavras do rio Cubatão, se dão posteriormente ao apogeu da mineração na região e não está diretamente relacionada às atividades mineradoras. A mineração aurífera no Planalto Curitibano e Litoral Paranaense foi importante na geração de recursos humanos, que viriam a participar da descoberta e exploração dos ricos depósitos mineiros, goianos e mato-grossenses. Contudo, a mineração não foi responsável pelo desenvolvimento de uma grande rede de centros urbanos, como ocorreu em outras regiões mineradoras do Brasil.
\end{abstract}

The auriferous mining in the ocupation of curitiba plateau and the paraná coastal zone (XVI-XVIIIth centuries)

\title{
Abstract
}

The territories presently known as Curitiba plateau and Paraná coastal zone were incorporated into the sphere of Portuguese colonization in the mid-seventeenth century, as a result of southward expansion of São Paulo economy. In the beginning of $\mathrm{XVII}^{\text {th }}$ century both areas were used by paulistas as indian slavery zones. Subsequently become zones of auriferous alluvial mining. The villages of Paranagua and Curitiba were founded in the period of more intense metal exploitation. The discovery of gold in Minas Gerais led mining activities in the region to decline. In the eighteenth century the establishment of "Sertão Route", connecting southern fields to Minas Gerais area, propitiate a second phase of villages foundation, related to cattle activities. The decline of mining in Curitiba and Paranaguá areas and the emerging of other economic activities accounted for the rearrangement of both regions, a process that takes all the eighteenth century. The development of the villages of São José dos Pinhais, near the Arraial mines, and Morretes, in the Cubatão mines, occurs after the 
AQUI

apogee of mining in the area, and was not directly related to mining activities. The gold mining on the Curitiba plateau and Paraná coast was important in the generation of human resources, who would participate in the discoveries and exploitations of the rich mineral deposits of Minas Gerais, Goiás and Mato Grosso. However, mining has not been responsible for the development of a large network of urban centers, as occurred in other mining regions in Brazil.

\section{Introdução}

A mineração aurífera foi muito importante na ocupação e consolidação do território brasileiro. A forma pela qual se deu esta ocupação e consolidação é consequiência da interação de diferentes formações sociais e econômicas num território historicamente delimitado. Dentre estas, as atividades mineradoras, que se iniciaram ao final do século XVI e adentraram o século XIX, atuaram eficazmente na construção do espaço geográfico brasileiro.

Entretanto, ao fazer uma leitura destes temas não raro encontramos uma grande fábrica de mitos e de proposições geopolíticas de cunho nacionalista, orientadas pela ideologia do "destino manifesto" (MORAES, 2001). Vistas a partir deste ponto de vista, a história destes eventos por vezes parece conter uma intencionalidade que acaba por obscurecer o significado dos processos de conquista e ocupação territorial no período colonial dentro de seu próprio contexto histórico.

O espaço geográfico aqui discutido se refere a duas entidades histórico-geográficas bem demarcadas: o planalto curitibano e o litoral paranaense. Entretanto, referir-se a uma entidade sócio-política chamada "Paraná" antes do século XIX é um equívoco, uma vez que este espaço geográfico é uma realidade administrativa que se traduz na Capitania de São Vicente e, já no século XVIII, na capitania de São Paulo. O desconhecimento deste fato pode levar a conseqüências 
AQUI

metodológicas que devem ser evitadas. $\mathrm{Na}$ verdade, a "História do Paranâ" é um tema demarcado pela História do Brasil Meridional e, numa perspectiva mais dilatada, pela História do cone sul americano (NADALIN, 2001).

O presente trabalho procura, dentro de suas limitações, fazer uma discussão sobre como se deu a ocupação deste espaço geográfico ao longo do período colonial e a importância da mineração aurífera neste processo. Como um estudo de caso, discutiremos as lavras de ouro ao longo do rio do Pinto, no atual município de Morretes, e as lavras do Arraial Grande, no município de São José dos Pinhais e suas respectivas relações com a urbanização da região em que estavam inseridas.

\section{Os caminhos primitivos e a ocupação do território}

\section{Caminhos da baia de Paranaguá}

A baía de Paranaguá, de início, despertou pouca atenção dos exploradores. Um dos prováveis motivos é a sua localização: apesar de ser a reentrância mais ocidental da costa leste brasileira, não possui grandes rios que possam estabelecer uma comunicação imediata com o interior. A grande barreira da Serra do Mar acompanhando a costa, com elevações de até $1800 \mathrm{~m}$, fez com que demorasse quase duzentos anos para que seus estreitos vales se constituíssem num caminho viável para o planalto (NADALIN, 2001).

A área da baia de Paranaguá, no século XVI, situava-se politicamente numa região limítrofe entre os estabelecimentos portugueses e castelhanos nesta parte da América. Neste período, as ambigüidades do tratado de Tordesilhas criaram uma "terra de ninguém" entre Cananéia, limite das ambições espanholas e a foz do Rio da Prata, limite das ambições portuguesas. Esta disputa, ao longo de quase todo o período, também contribuiu para retardar a ocupação da região.

Os caminhos para o litoral paranaense eram primitivamente feitos entre Cananéia e a ilha de Superagui pelo canal do Ararapira (Fig. 1). Hans Staden, marinheiro alemão, é o primeiro europeu a 
AQUI

citar a ilha de Suprawai (Superagui), aonde chega em 1549, fugindo de uma tempestade. Staden, aliás, ali já encontra portugueses, vindos de Cananéia (STADEN, 1999). MAACK (1968) observa que até o começo do século XVII o topônimo Superagui é mais freqüente que o topônimo Paranaguá nos relatos de viagens e nos mapas produzidos no início da ocupação portuguesa.

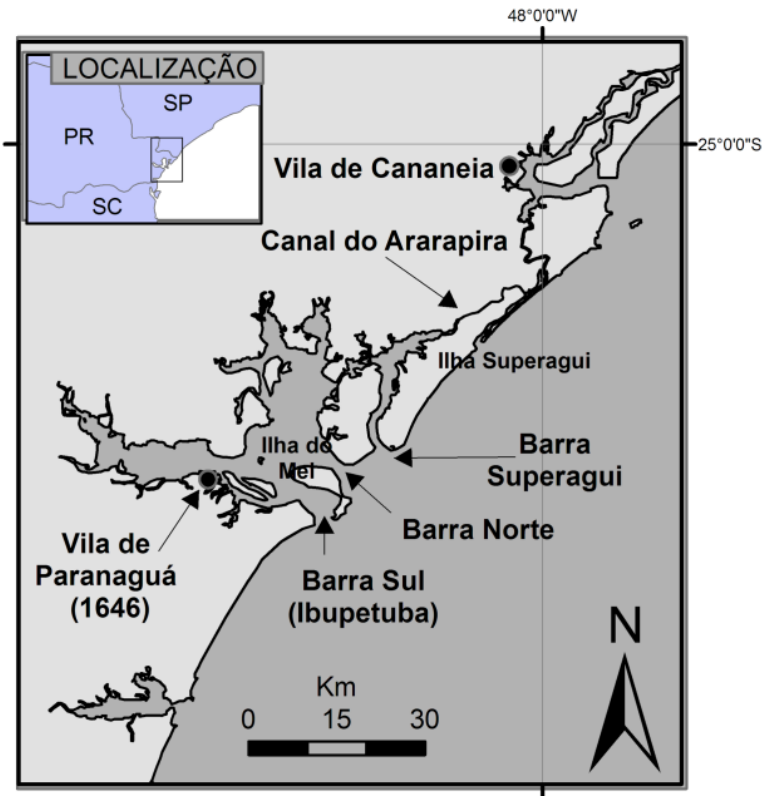

FIGURA 1: Os caminhos primitivos da baia de Paranaguá, com destaque as três barras da baia e para o canal do Ararapira, principal via por água a partir de Cananéia.

A baia de Paranaguá não atraiu de imediato a atenção dos exploradores e colonizadores. O topônimo "Paranaguá" somente é encontrado no mapa-múndi pela primeira vez a partir de 1610 (MAACK, op cit.). O acesso primitivo ao interior da baía era feito pela ilha de Superagui, pelo canal do Ararapira (Fig. 1). A barra norte da baia de Paranaguá deve ter sido mais usada a partir da 
AQUI

fundação da vila homônima, em meados do século XVII. Para proteger esta barra, no século XVIII foi construída a fortaleza na Ilha do Mel. A passagem pelo Canal da Galheta ou Ibupetuba só se tornou o principal acesso a partir de meados do século XX.

A primeira referência à Paranaguá em documentos escritos é de 1614, com a concessão da sesmaria a Diogo de Unhate (MARTINS, 1945). Não obstante, Unhate era morador em Santos em 1636 e foi um dos fundadores de São Sebastião. Para Martins (op.cit) é bastante duvidoso que Unhate realmente houvesse tomado posse de sua sesmaria.

A primeira representação cartográfica exclusiva da baia de Paranaguá é o mapa de Albernás, executado em 1631 (PICANÇO \& MESQUITA, 2011; SOARES \& LANA, 2009), que representa tão somente as três entradas de sua barra. Este mapa, feito com base nas observações de D. Jerônimo Ataíde, para o cartógrafo português João Albernás, mostra o pouco conhecimento que se tinha do interior da baía até meados do século XVII. A primeira planta detalhada da baía de Paranaguá data de 1653 e é executada provavelmente por Pedro de Souza Pereira, no auge da exploração aurífera na região. Conforme Picanço (2009), este mapa, além das feições geográficas reconhecidas, tais como ilhas, promontórios, rios, a serra do Mar e as "vilas" de Curitiba e Paranaguá, é um dos primeiros a mostrar com riqueza de detalhes o interior da baía. Nele consta a localização das famosas minas de ouro de Paranaguá em vales dos rios Cubatão, Cacatu, Cachoeira e Faisqueira. A barra norte e a barra sul foram sondadas por Pedro de Souza Pereira, cuja profundidade em braças consta no referido mapa. 


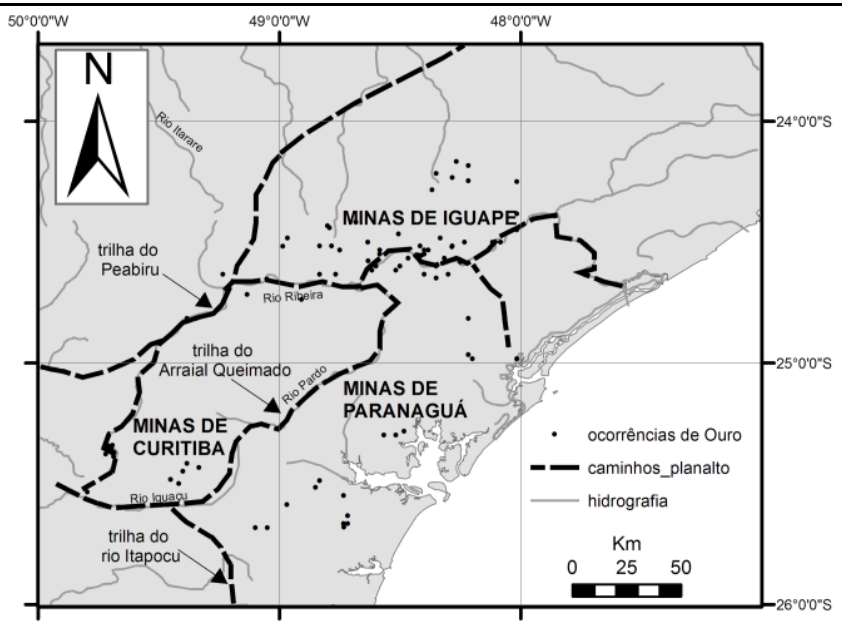

FIGURA 2: Os caminhos primitivos do planalto curitibano e sua ligação com as regiões mineradoras (MAACK, 1968). Para comparação, estão localizadas as atuais ocorrências de ouro conhecidas na região (CPRM, 1994).

\section{Caminhos do planalto curitibano}

O Planalto Curitibano nos séculos XVI/XVII era cruzamento de várias rotas pré-cabralinas (figura 2), entre as quais se destacam as trilhas do Peabiru (MAACK, 1968; CARDOSO \& WESTPHALLEN, 1981). O caminho mais fácil para o Planalto Curitibano nesses tempos era subindo o rio Ribeira de Iguape até as nascentes do rio Açungui, pela trilha do Peabiru, quando então se alcançavam os Campos Gerais. Outro caminho era igualmente pelo Ribeira de Iguape, mas seguia-se pelo rio Pardo até as cabeceiras do rio Capivari, quando se atingia os campos de Curitiba pela trilha do Arraial Queimado.

A trilha do Peabiru que atravessava quase todo o atual estado do Paraná até Sete Quedas. Atravessando o Paraguai, a trilha podeia chegar até a atual Bolívia. O Peabiru, pelo vale do rio 
AQUI

Ribeira de Iguape, foi provavelmente o caminho da expedição de Pero Lobo, trucidada em 1532 pelos indígenas no vale do Iguaçu.

Pelo sul, a partir das ilhas de São Francisco e de Santa Catarina, o caminho mais viável para o Planalto Curitibano era pelo vale do rio Itapocu (figura 2), por onde foram provavelmente realizadas as entradas de Aleixo Garcia (1526) e de Cabeza de Vaca (1541-42), rumo ao interior do continente. Em sentido contrário, vindo do Paraguai, tem-se a expedição de Ulrich Schmidell (1552-53), que atravessa desde o vale do Uruguai até o Peabiru. Pelo Peabiru, Schimidell e seus companheiros alcançaram Santo André da Borda do Campo, onde foram provavelmente acolhidos por João Ramalho (MAACK, 1968).

Assim, desde o inicio da ocupação e colonização portuguesa, e mesmo antes, o planalto curitibano era um território de passagem, que comunicava o litoral, pelo vale do Ribeira e, secundariamente, pelos vales dos rios Itapocu e Itajaí, com o interior do continente. Com isso, dizemos que os movimentos iniciais da ocupação foram realizados através do planalto curitibano, e não pela baía de Paranaguá, o que implicou numa evolução diferente para cada região. O planalto curitibano teve seu povoamento inicial principalmente através dos caminhos do vale do rio Ribeira. Este era, durante boa parte do século XVII, o melhor caminho entre o planalto e a marinha. Por exemplo, João Manuel França, último capitão-mor da Capitania de Paranaguá, pagava em Iguape - e não em Paranaguá - o imposto do quinto sobre o ouro que extraía de Itambé, nas proximidades da atual Campo Largo, conforme as anotações de Young (1907) e Leão (1926).

As comunicações do Planalto Curitibano com a baia de Paranaguá eram mais difíceis, dada à barreira geográfica da serra do Mar. Começaram a ser mais frequientes somente em meados do século XVII. O primeiro caminho que se tem notícia era o caminho do rio Curitibaíba (termo da língua-geral que, segundo Leão (1926) significa, literalmente, "Caminho de Curitiba"), seguindo aproximadamente o traçado da atual Estrada da Graciosa. O caminho do rio Arraial (MOREIRA, 1971), de inicio secundário, 
AQUI

foi se tornando importante ao longo do século XVII (ver adiante). $\mathrm{O}$ caminho do Arraial ligava as duas maiores zonas auríferas, as lavras do rio Cubatão (hoje Nhundiaquara) e as lavras do Arraial, no atual município de São Jose dos Pinhais. Ao longo do século XVIII, o caminho, ou pelo menos alguns de seus trechos, foram diminuindo de importância, como veremos adiante. Os caminhos do Itupava e da Graciosa são posteriores, já do século XVIII.

\section{Descoberta e exploração das lavras vicentinas}

$\mathrm{Na}$ região vicentina, as primeiras entradas conhecidas em busca de ouro datam do inicio da colonização, porém sem resultados apreciáveis (NOGUEIRA \& MAFFEI, 1966).

Apesar dos esforços dos portugueses na tentativa de descobrirem minas, principalmente minas de prata, a exemplo do conquistado por Castela, os metais preciosos demoraram a aparecer. O maior esforço na busca, e que culmina com a descoberta de ouro, é realizado durante o período da União Ibérica (1580-1640).

São Paulo se torna uma região diferenciada depois dos governos de Dom Francisco de Souza, entre 1591-1598 e 16051611, embora não a mais rica ou a mais importante entre os estabelecimentos coloniais portugueses (MONTEIRO, 1994). O fomento à agricultura, sobretudo a triticultura, foi um dos pilares das reformas promovidas por D Francisco, que, reproduzindo os congêneres espanhóis, organizou a produção de alimentos para sustentar as minas de ouro que vinham sendo instaladas. Nessa época, com a vinda de mineiros, principalmente espanhóis, são exploradas as jazidas de aluvião ao redor de São Paulo na serra do Jaraguá, Guarulhos, Itapecerica. Desta época em diante, verifica-se o crescimento, nos testamentos da época, das quantidades de ouro e de ferramentas de mineração (NOGUEIRA \& MAFFEI, 1966). Data desta época (1603, com modificações em 1618), a primeira legislação mineral da colônia, uma cópia da legislação espanhola. 
Existem evidências de guerras de apresamento aos indígenas da região do planalto curitibano por bandeiras paulistas em 1585/1594 (Jorge Correia) e 1595 (Manoel Soeiro) no "país dos carijós", uma região que abrangia os vales do Itapocu e Iguaçu, nos atuais estados de Santa Catarina e Paraná, conforme Romário Martins (1945). Ao mesmo tempo, a região de Paranaguá foi mais visitada pelos santistas por via marítima também "para fazer resgates", ou seja, para capturar indígenas.

A partir de meados do século XVII a mineração aurífera se expande lentamente para o sul. A primeira referência documental à existência de ouro na região de Paranaguá é de 1622, segundo Nogueira \& Maffei (1966). À medida que prossegue a expansão para o sul, segue-se a fundação de novas vilas. Assim, Iguape é fundada em 1637, Paranaguá em 1648 e, no planalto, Curitiba tem sua primeira fundação em 1668. A vila de Curitiba seria definitivamente fundada em 1693, após a morte do capitão povoador de Paranaguá, Gabriel de Lara, o qual se opunha à fundação de nova vila no planalto (LEÃO, 1926; MARTINS, 1945).

A produção de ouro em toda esta região era pequena, preocupando as autoridades coloniais. O próprio governador-geral Salvador Correa de Sá e Benevides foi a Paranaguá verificar as "minas" (1660), mas não se entusiasmou com o que viu. Em 167879 vêm a São Paulo D. Rodrigo de Castel Blanco, a mando do rei. Depois de verificar as lavras em atividade, tanto em Paranaguá quanto nos campos de Curitiba, retirou-se para a recém-descoberta Sabarabuçu (as futuras Minas Gerais), onde foi assassinado pelos paulistas.

Segundo as estimativas de Noya Pinto (1979), as minas de Paranaguá, Curitiba e Iguape devem ter produzido, durante o período 1680-97, o equivalente a 50 a $80 \mathrm{~kg}$ de ouro anuais. No período 1697-1735, os dados apontam para uma produção de 20-30 kg/anuais. 
AQUI

\section{Século XVIII e a reorganização do território}

A partir da descoberta das Minas Gerais, no século XVIII, a economia paulista, depois de um longo período de estagnação, se articulou com a economia das regiões mineradoras. A abertura do caminho do Viamão em 1728-1730, que depois seria conhecido como "Estrada Geral" ou "Estrada do Sertão", iniciou um novo ciclo de comércio e revigorou a economia da região. O ganho na região paulista, a partir de então, está ligado ao comércio, à criação de animais e à procura de pastos suficientes e superiores para engordar e ampliar a criação. $O$ território paulista passa a ser um território de passagem entre as Minas Gerais e os campos do sul. Em face da nova sociedade campeira que surge nos planaltos do sul, a mineração local ainda subsiste, porém de maneira subordinada.

A descoberta e exploração do ouro de Minas Gerais, Mato Grosso e Goiás, no século XVIII, mudam drasticamente a estrutura do espaço territorial brasileiro. Nesse momento, a mineração de ouro "expande o Brasil para o coração da América e fixa núcleos estáveis e definitivos", no dizer de Caio Prado Junior (1975, pg. 37). A preocupação da metrópole em relação ao Brasil é articular os territórios mineiros às demais regiões da colônia em termos militares e comerciais, garantindo o sustento da atividade. Posteriormente, a partir do processo dos Tratados de Limites com as possessões espanholas, torna-se necessário ocupar e demarcar o território. Estes dois processos em conjunto obrigam a metrópole à uma ocupação que garanta efetivamente a posse do território.

O planalto curitibano, assim como toda a economia paulista da época, articula-se com a economia mineira, constituindo um setor de passagem para a florescente pecuária sulina. Os territórios ao longo da estrada, nos Campos Gerais, eram utilizados como pastagem e/ou invernada, alugado pelos proprietários aos tropeiros (STRAFORINI, 2001).

A partir daí, começam a surgir às vilas dos Campos Gerais: Castro, Lapa, Palmeira, Piraí e Tibagi no século XVIII; Ponta 
AQUI

Grossa, Jaguariaíva e Guarapuava, no século XIX (CARDOSO \& WESTPHALLEN, 1986). No litoral, Guaratuba e Antonina surgem no século XVIII, ligadas ao desenvolvimento da região e às entradas organizadas com finalidades militares. Como veremos com detalhe adiante, Morretes, no litoral, e São José dos Pinhais, nos campos do alto Iguaçu surgem no século XVIII e são tornadas vilas no século XIX.

A maior parte destas vilas, principalmente as dos Campos Gerais, surge como ranchos, vendas, pousos, estalagens ou fazendas no caminho das tropas (STRAFORINI, 2001). Com o desenvolvimento da região, estes lugarejos vão lentamente aumentando de importância até constituírem vilas e cidades. Guaratuba, no litoral, surge por determinação do governador D Luiz Antonio de Souza Botelho Mourão, o Morgado de Mateus, preocupado em fundar uma vila para controlar um eventual avanço das tropas castelhanas que invadiam com frequência o sul. Com a mesma preocupação, faz erguer a fortaleza de Nossa Senhora dos Prazeres, na Ilha do Mel para proteger a barra norte de Paranaguá (LEÃO, 1926).

Ao contrário das Minas Gerais, Goiás e Mato Grosso, onde a quantidade e a qualidade dos jazimentos de ouro formaram uma grande teia de arraiais que se tornaram vilas e cidades, no caso paranaense o mesmo não se deu. Numerosos topônimos lembram a mineração na região, como Faisqueira, Ouro Fino, Guapiara, Bateias, entre outros. Lavras antigas, como Itambé, Conceição, Botiatuva, Uvaporunduva, ainda estão presentes na toponímia. Muito embora sejam comumente referidas na historiografia paranaense do século XX como "cidades do ciclo do ouro", estas novas cidades não têm relação com a mineração. São as cidades do Paraná tradicional (CARDOSO \& WESTPHALLEN, 1986). Com exceção de Paranaguá e Curitiba, nenhuma outra lavra seiscentista tornou-se vila ou cidade. 
AQUI

\section{Morretes e São José dos Pinhais}

Morretes e São José dos Pinhais são exemplos de cidades não relacionadas ao "ciclo do ouro vicentino", apesar de terem se desenvolvido próximas da região de duas das mais prolíficas lavras antigas, as lavras do Cubatão e as do Arraial. No litoral, as lavras de atividade mais duradoura ocorreram no vale do rio Cubatão (atual Nhundiaquara), principalmente ao longo de seu afluente, o rio do Pinto. As lavras do Cubatão já constam do mapa feito em 1653 por Pedro de Souza Pereira (PICANÇO, 2009). Nessa carta, as lavras são representadas pelas inúmeras indicações de 'minas". No século XVIII são famosas as lavras do Penajóia, no vale do rio do Pinto, atravessada pela estrada do Arraial (Leão, 1926). Observa-se ao longo desta estrada a presença de um grande número de pequenos lugarejos e pequenos portos fluviais. Os povoados de Anhaia e Água Rasgada (Figura 3), entre outros, eram pequenos portos fluviais e/ou antigas áreas de lavra (Moreira, 1971). O Porto do Padre Veiga, ou Porto de Curitiba, era outra destas localidades. Neste local eram feitos os traslados via fluvial até Paranaguá. Pelo caminho inverso, pegava-se o Caminho do Arraial, que atravessava as lavras do mesmo nome e se ia à Curitiba atravessando a Serra. Quando se compara estas áreas de lavras de ouro antigas, observase a sua coincidência com as áreas de pesquisa de ouro aluvionar ou ouro secundário dos bloco de pesquisa da MINEROPAR nos anos 1980 (CUNHA NETO, 1984), assim como com os garimpos de ouro do século XX (CPRM, 1994).

A atual cidade de Morretes surge a partir de uma determinação do Ouvidor Pardinho, de 1721, ordenando que a Câmara de Paranaguá demarque 300 braças em quadra para a cidade, que deveria reunir as comunidades dispersas pelas áreas das lavras (LEÃO, 1926). A área é demarcada pela Câmara de Paranaguá somente em 1769, no antigo porto dos Três Morretes. Nesta nova localidade é construída a matriz de N.S. do Porto, quando a vila é elevada a freguesia. Em 1841, neste local, Morretes foi elevada à cidade. 

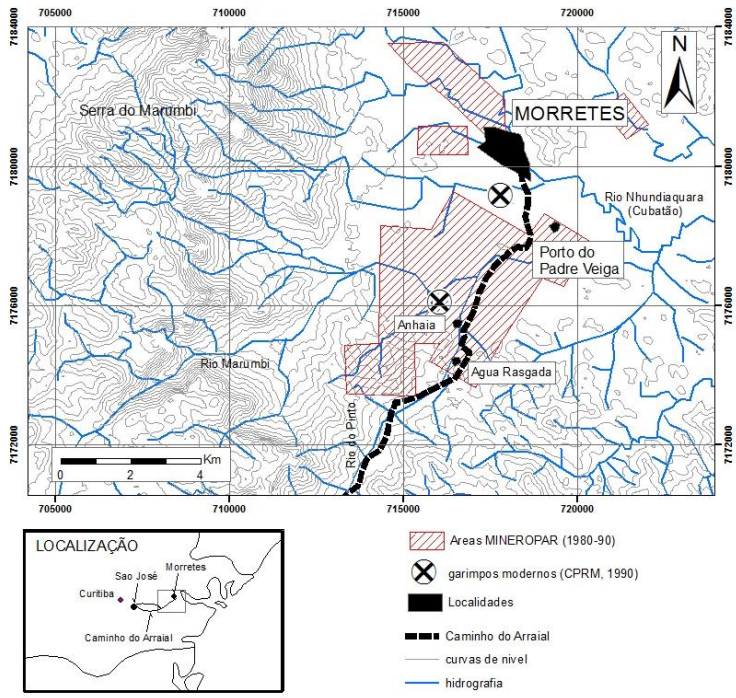

FIGURA 3: Mapa de localização das antigas lavras de ouro de Porto do padre Veiga, Anhaia, Água Rasgada e do Caminho do Arraial do século XVII. Para comparação, é indicada a localização da atual cidade de Morretes e das áreas de pesquisa de ouro efetuada pela MINEROPAR nos anos 80 (Cunha Neto, 1984) e garimpos da CPRM, 1990.

No caso de Morretes, verifica-se que a urbanização surge como um ordenador de território, visando reunir a população dispersa pelas antigas áreas de lavra, num contexto econômico bastante distinto do original. A nova vila surge e se desenvolve, no final do século XVIII, como entreposto de mercadorias entre o litoral e os Campos de Curitiba, através dos portos de Paranaguá e Antonina, via os novos caminhos de Itupava e da Graciosa. A atividade pecuária dos campos de Curitiba se constituía na principal atividade econômica da região e motivadora do desenvolvimento da região (MARTINS, 1945). 
No planalto, uma das lavras com maior período de atividade foi a do Arraial Grande (figura 4), ao longo do rio de mesmo nome, no atual município de São José dos Pinhais. As minas do Arraial Grande foram lavradas em 1661 por Balthazar Carrasco dos Reis, um dos capitães-povoadores de Curitiba (LEÃO, 1926). Em 1732, estas lavras eram as mais produtivas do planalto, como se deduz das guias de ouro de Curitiba enviadas para a casa de fundição de Paranaguá (NEGRÃO 1921). Em 1741, há documentos mostrando que as "minas" eram exploradas por Gaspar Carrasco dos Reis, Baltazar Veloso da Silva e Salvador de Albuquerque (MARTINS, 1945). O esgotamento da lavra, por volta de 1750 , determinou o abandono do Arraial. Num termo de vereança da câmara de Curitiba, em 1760, certo João Simões declara que, dado o reduzido numero de pessoas envolvidas na lavra, os caminhos do rio Arraial até o cume da serra não estavam sendo cuidados como deveriam (BAMC, 1921).

Com o esgotamento das lavras, ocorre uma progressiva mudança da população para as regiões do planalto, em detrimento do antigo Arraial. A antiga freguesia de Bom Jesus dos Perdões, fundada em 1690 e mais próxima das lavras, perde o status de freguesia em 1714. A atual São José dos Pinhais surge com o deslocamento populacional para o trecho, no qual a antiga estrada do Arraial cruza o rio Iguaçu (LEÃO, 1926; COLNAGUI et al., 1992). A reorganização do território se completa em 1756/57, com a instalação da freguesia de São José dos Pinhais, elevada à vila em 1852. 

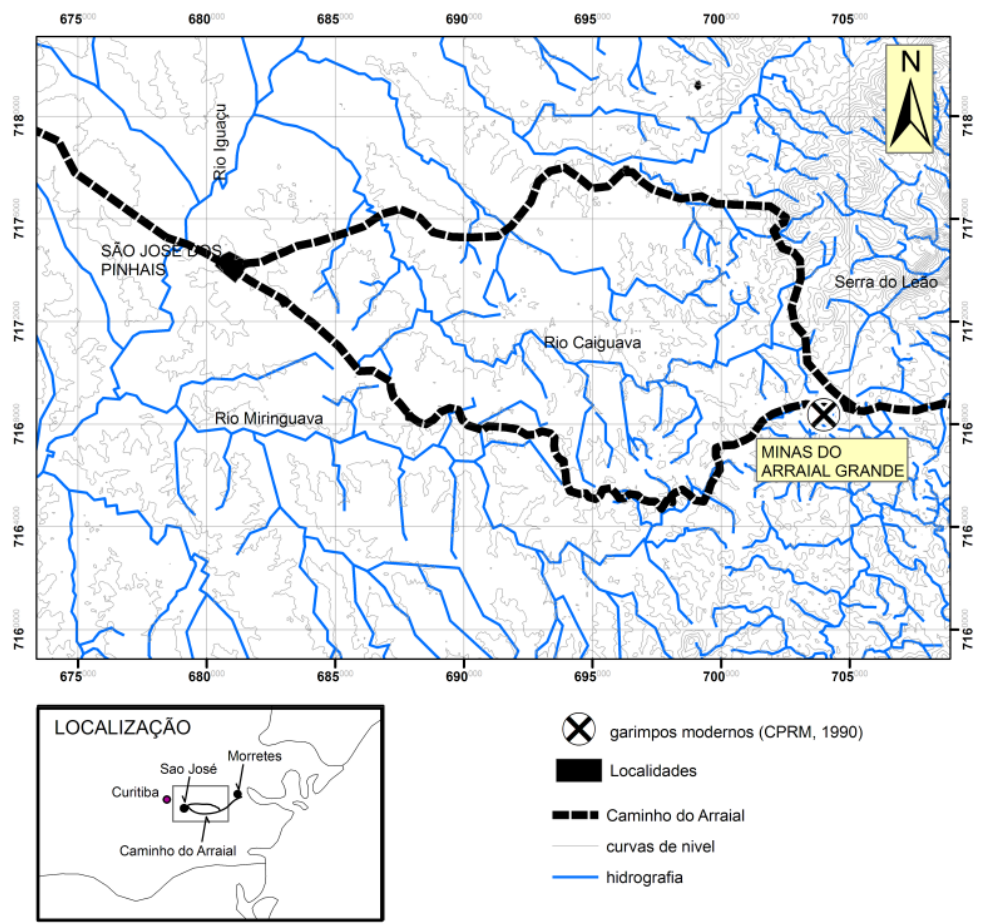

FIGURA 4: Mapa de localização do Caminho do Arraial e das Minas do Arraial. Também são indicadas a atual cidade de São José dos Pinhais e as áreas de modernos garimpos listados pela CPRM (1994).

\section{Discussoes e conclusões}

A mineração é uma atividade econômica caracterizada pela exploração de recursos não renováveis, com um ciclo de vida bem definido. A mineração nos gold rushes inicia-se geralmente com um período inicial de grande vitalidade econômica. Entretanto, a partir do momento em que não existam novas descobertas de 
jazidas, o natural declínio das atividades mineradoras pode deixar para trás somente um rastro de cidades fantasmas, como já verificado em tantas partes do mundo. Portanto, a criação de espaço fomentada pela atividade mineradora não mantém necessariamente a ocupação de um determinado território. A população ligada à mineração tende a seguir migrando, rumo à próxima riqueza.

A atividade de mineração, no caso paulista, está inicialmente ligada à perspectiva quinhentista e seiscentista da aventura, da "correria pelo sertão", no dizer de Sergio Buarque de Holanda (BUARQUE DE HOLANDA, 1960). A mineração seiscentista, principalmente depois do governo de D. Francisco de Sousa, é um bom álibi para a caça ao índio. Entrando no sertão e não encontrando minerais, trazer algumas peças do "gentio da terra" era uma desculpa usada pela infração das ordens régias, que proibiam a escravidão indígena. No entanto, e principalmente por esta causa, a mão de obra nas minas vicentinas é majoritariamente indígena.

A urbanização, instrumento poderoso de ocupação e colonização, teve na região estudada duas etapas bem distintas: a primeira, no século XVII, com o surgimento das vilas de Iguape, Paranaguá e Curitiba, ligadas principalmente ao surgimento da mineração; e a segunda, a partir da segunda metade do século XVIII, com o surgimento das pequenas cidades que seriam chamadas pela historiografia paranaense de "Paraná Tradicional" (CARDOSO \& WESTPHALLEN, 1986). Este segundo momento está associado à articulação econômica da colônia com as novas regiões mineradoras e com a necessidade de ocupação do território durante a questão dos tratados de fronteiras com as colônias espanholas.

A ocupação do território geográfico, no qual se insere o Planalto Curitibano e o Litoral Paranaense, no período colonial está intrinsecamente ligada à primitiva expansão paulista, nos séculos XVI-XVII, associada tanto à caça ao índio quanto à atividade mineradora. A ocupação portuguesa da região, no entanto, só se dá durante o período da União ibérica. Até então, a região ao sul de 
AQUI

Cananéia e entre os rios Tibagi e Paraná estava dentro da órbita castelhana (PICANÇO \& MESQUITA, 2010).

A vocação de Curitiba como zona de junção dos caminhos do planalto vem desde os tempos pré-colombianos, com os caminhos do Peabiru. Os caminhos de Paranaguá são marítimos, a partir de Cananéia via canal do Ararapira e, só posteriormente, via a barra de Paranaguá. A conexão Paranaguá-Curitiba se dá já no final do século XVII, com a abertura de diversos novos caminhos que atravessavam a barreira da Serra do Mar.

Após um período de apogeu no século XVII, o que se verifica no século XVIII é um esvaziamento do território paulista, com a migração da população para as novas regiões mineradoras. A região do Planalto Curitibano passa a se constituir em uma área de passagem entre as Minas Gerais e as áreas pastoris do extremo sul, a partir do estabelecimento das rotas tropeiras em meados do século XVIII.

Embora nunca correspondesse em termos de quantidade e qualidade ao que desejavam os mineradores e as autoridades coloniais, a atividade mineradora na região de Curitiba e Paranaguá - e Iguape - teve um duplo papel, seja na indução dos assentamentos coloniais na região, seja na geração de conhecimentos e recursos humanos que atuaram na descoberta das lavras mineiras, goianas e mato-grossenses.

No entanto, a mineração paulista não foi importante o suficiente para definir a ocupação do território via assentamentos urbanos da região. As vilas de Iguape, Paranaguá e Curitiba são as únicas diretamente relacionadas com a mineração de ouro no século XVII, e fundadas praticamente na mesma época. Com exceção de pequenas localidades e de topônimos esparsos, a mineração deixou poucos traços. As demais cidades e vilas são produtos do reordenamento do território efetuado durante o século XVIII, quando da inserção da região como zona de trânsito entre a zona pecuarista do extremo sul e as Minas Gerais. 
AQUI

\section{Referências bibliográficas}

Boletim do Arquivo Municipal de Curitiba (BAMC), XXVI, 7576. Termo de vereanssa (sic) de 31 de $^{2} \operatorname{Dez}^{\circ}$ de 1760 (pessoas trabalhando por Mineiro no Arraial Grande). Curitiba, Prefeitura Municipal, 1921.

Buarque de Holanda, S. Mineração: antecedentes luso-brasileiros. In: Buarque de Holanda, S. (ed.) História Geral da Civilização Brasileira. t. I, vol. II, São Paulo: Difusão Européia do Livro,pg. 228-258,1960.

Cardoso, J.A. \& Westphallen, C.M. . Atlas Histórico do Paraná. Livraria do Chain editora, 1986.

Colnagui, MC, Magalhães filho, FBB; Magalhães, MDB (1992) São José dos Pinhais - a trajetória de uma cidade. Prefeitura municipal de São José dos Pinhais, 282 p. , 1992.

Companhia de Pesquisa de Recursos Minerais - Serviço Geológico do Brasil (CPRM). Pesquisa Mineral - jazimentos de ouro. SER/BH, 482 pp. 1994.

Cunha Neto, A.F. (1984) Pesquisa de ouro nos aluviões da região de Morretes - litoral do Paraná. In: Congresso Brasileiro de Geologia, 33․ Anais. Sociedade Brasileira de Geologia, vol X: 4067-4079. 1984.

Leão, E. Minas de Paranaguá. In: Leão, E. Dicionário Histórico e Geográfico do Estado do Paraná. Tomo VII , pp 1322-1348, 1926.

Maack, R. Contribuição à história das explorações geográficas e geológicas do estado do Paraná. In: Maack, R. Geografia Física do Paraná. Curitiba, BADEP, UFPR, 450 pag, 1968. 
AQUI

Maffei, L.A. \& Nogueira, A,R. O ouro na capitania de São Vicente nos séculos XVI e XVII. Bol Inst. Hist. SP, pp 7-135, 1966.

Martins, R. Historia do Paraná. Curitiba, Travessa dos Editores, , 524 pag., 1995.

Monteiro, J.M. Negros da Terra - índios e bandeirantes nas origens de São Paulo. Companhia das Letras, 1995, 300 pag.

Moraes, A.C.R. Bases da formação territorial do Brasil - o território brasileiro no "longo" século XVI. São Paulo, Hucitec, 420 pag. , 2001.

Moreira, J.E. Caminhos Antigos do Litoral. Curitiba, SEED, 1971.

Nadalin, Sergio Odilon Paraná: ocupação do território, população e migrações. Curitiba, SEED, 107pag. , 2001.

Negrão, F. Cartas das guias de ouro extrahido em Curytiba e remetido à Caza de Fundição de Paranaguá. Boletim do Arquivo Municipal de Curitiba, X, 83-108, 1921.

Noya Pinto, V. O Ouro Brasileiro e o Comércio AngloPortuguês. Coleção brasiliana, vol. 371. São Paulo, Companhia Editora Nacional, 2a ed., 1979.

Paes Leme, P.T.A. [1772] Notícias das minas de São Paulo e dos sertões da mesma capitania. Edusp-Itatiaia, pag 29-240,1980.

Picanço, J.L., Comentários sobre o artigo “O Paraná na história da Mineração no Brasil no século XVII”, de Liccardo et alii (2004). Bol.Paranaense de Geociências. 56: 121-123, 2005.

Picanço, J.L. \& Mesquita, M.J. O Cristal, o Ferro e o Sal: Recursos Minerais do Antigo Guairá (1557-1632). Terrae Didática 6(2): 67-75, 2010. 
AQUI

Picanço, J.L. A Pesquisa Mineral No Século XVII: O Mapa de Pedro de Souza Pereira (1653). Anais do I Simpósio LusoBrasileiro de Cartografia Histórica. Ouro Preto, Centro de Referencia em Cartografia histórica (UFMG), 2009. In: (http://www.ufmg.br/rededemuseus/crch/resumos-trabalhos.htm).

Prado Jr, C. História Econômica do Brasil. São Paulo, Brasiliense, 1975, 280 p., 1975.

Soares C.R. e Lana, P.C. Baia de Paranaguá: Mapas e Histórias. Curitiba, Ed UFPR, 98 p. , 2009.

Staden, Hans Primeiros registros escritos e ilustrados sobre o Brasil e seus habitantes. Trad. Angel Bojadsen. São Paulo, Primeiro Nome, [1557] 1999.

Straforini, R. No caminho das Tropas. Sorocaba, TCM, 130 pp. , 2001.

Young, E. Subsídios para a história de Iguape. Mineração de ouro. Bol. Inst. Hist. Geog. SP, 6: 400-435, 1904. 